\title{
Social technologies for cross-functional product development: SWOT analysis and implications
}

\author{
Marco Bertoni \\ Luleå University of Technology \\ marco.bertoni@ltu.se
}

\author{
Koteshwar Chirumalla \\ Luleå University of Technology \\ koteshwar.chirumalla@ltu.se
}

\author{
Christian Johansson \\ Luleå University of Technology \\ christian.johansson@1tu.se
}

\begin{abstract}
In product development, innovation means bringing together people with different expertise to develop breakthrough product and service offers. In spite of their potential, cross-functional efforts are not yet adequately supported from a knowledge perspective, asking for a more open and bottom-up approach for knowledge management. The paper aims to investigate how social technologies can enhance collaboration and knowledge sharing in complex, cross-functional and cross-organizational product development projects, highlighting the role of weak ties as enablers for more innovative design processes. Emerging from data collected in two case studies within the European aeronautical industry, it applies the StrengthsWeaknesses-Opportunities-Threats (SWOT) framework to highlight how wikis, blogs, forum or microblogs can shorten lead-time and increase the quality of early design decisions. Furthermore, it elaborates on how the design team can enhance its perception of the needs to be addressed and leverage its capability to develop solutions for the task at hand.
\end{abstract}

\section{Introduction}

In recent years, it is becoming common for companies in the manufacturing business to build strategic alliances with customers, suppliers, research centers [1], and even competitors [2] to radically develop (or even just to incrementally innovate) new product/service solutions. In aerospace, for instance, the V2500 aero engine family [3] has been developed by the IAE International Aero Engines AG, a multinational consortium led by Rolls Royce and Pratt \& Whitney, together with the Japanese Aero Engines Corporation (JAEC) and MTU Aero Engines. Similarly, the CFM56 aero engine product line [4] is developed by CFM International, a company jointowned by the French SNECMA and General Electric Aviation.

The development of technologically complex products requires a wide range of skills, knowledge and expertise, which are difficult to find within a single company function or even within a single organization [5]. Moreover, hardware-centered offers are increasingly complemented with different combinations of software and services to satisfy increasingly sophisticated customer needs, as well as to secure aftermarket activities (e.g., Product Service Systems [6], Functional Products [7] and Industrial Product Service Systems [8]).

In this scenario the design problem becomes increasingly wicked [9]. It can be adequately addressed only by involving in the decision-making process people from different functional areas, and with heterogeneous competencies and skills [10]. The development of collaborative decision-making capabilities represents a main objective, as well as a challenge, for these partnerships, which asks for enhanced methods and tools to acquire knowledge from a large network of independent and geographically dispersed peers [11].

\section{Motivation and objectives}

Nowadays, the existing technological support for knowledge sharing within product development still focuses on explicit knowledge, that is, knowledge is embodied into 3D CAD (Computer Aided Design), and CAE (Computer Aided Engineering) models, as well as in PDM (Product Data Management), PLM (Product Lifecycle Management) and KBE (Knowledge Based Engineering) applications.

This contrasts with what observed by Bell [12], who found that $80 \%$ of organizational knowledge is stored in people's heads, $16 \%$ is stored as unstructured data, and only $4 \%$ is formalized in a structured form. These figures are emphasized in cross-functional development efforts, and represent an obstacle when engineers require authentic information, expert help, or need to retrieve quality knowledge.

Often cross-functional team members find it cumbersome or even impossible to interact with domain-specific applications - such as the ones above resulting in situations where the vast majority of 
people who might have knowledge about the emerging aspects of the product cannot contribute in populating the knowledge base [11]. Hence, successful product/service development efforts depend on the capability to provide ad-hoc collaboration platforms, where knowledge can flow smoothly and informally across functional and organizational walls, establishing personal relationships that transcend local boundaries both socially and geographically.

The ground hypothesis of this study is that the knowledge base for cross-functional and crossorganizational development projects can be leveraged (i.e., the knowledge elements on which design decisions are taken can be improved in quantity and quality) by complementing 'top-down' knowledge sharing systems with 'bottom-up' solutions, to tap into dispersed team's skills, capabilities, and competences in other words, on the 'wisdom-of-the-crowd' [13].

Emerging from two case studies in the aeronautical supply chain, the paper investigates how social, bottom-up or "lightweight" (compared to the more "heavyweight" traditional solutions) knowledge sharing systems may supply to the increasing demand of knowledge of these teams. Accordingly, the two key objectives of the paper are to:

- Discuss the role of weak ties as enablers for more collaborative and innovative crossfunctional development projects;

- Analyze the key mechanisms introduced by social technologies that can support these teams in shortening the decision making time and in increasing the quality of early design decisions.

\section{Methodology}

Two different industrial case studies served as basis for the research. The first one involved Company A, an aircraft engine component manufacturer, which has pioneered, since a couple of years, the development and implementation of Web 2.0 tools in its product development environment. The study has analyzed the knowledge flows between the company, its suppliers, customers, and wholly owned subsidiary, to understand how cross-functional teams create, process, share, and reuse information in their regular activities.

The second study was performed at a supplier level (Company B). It analyzed the internal and external knowledge flows in relation with the existing Document Management Systems (DMS), in the light of strengthening the connection between the company and the customers in the network.

Figure 1 shows where the case studies are positioned within a simplified aeronautical supply chain, and details the cross-company knowledge flows analyzed during the study.

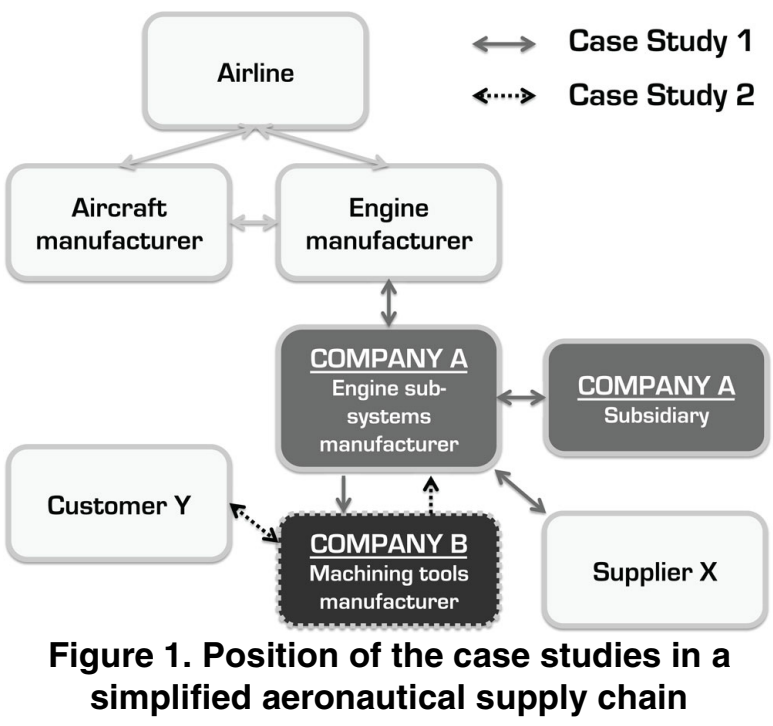

The companies were chosen as the main research context because of their rich experience with crossfunctional teams. The study has resulted in $37 \mathrm{semi-}$ structured interviews and 6 focus groups with people from the participating companies. The interview respondents belonged to different company functions (product development, customer support, marketing, production and IT service) and to different levels of the company hierarchy (process owners, project managers, company specialists and system users).

The data gathering activity was performed in seven separate sessions at the respective company facilities between June 2008 and January 2011. Each interview was audio-recorded, transcribed, spell-checked and validated by the respondents. The excerpts presented in this paper have been taken from these recordings.

The Strengths, Weaknesses, Opportunities, and Threats (SWOT) framework has been used throughout the analysis to classify favorable or unfavorable factors to the adoption of social technologies within product development, from which to define the requirements for a system mock-up. Given the cross-functionality of the project context, the SWOT has been chosen to stimulate the interaction across the functional boundaries. In spite of its simplistic structure [14] and lack of diagnostic capacity [15], the widespread adoption and recognizability of the framework [16] have facilitated stakeholders who do not frequently work together to engage in conversations [17][18] and to nurture discussions that would not have emerged in the normal course of a business struggling with shortterm issues [19]. The SWOT has essentially played the role of boundary object [20][21], enabling the 
integration of knowledge across boundaries [22], that is, as a focal point around which knowing-in-practice could arise [23].

\section{The power of weak ties within cross- functional development teams}

Within product development, it has been observed that engineers and scientists very often turn to a person for information rather than to a database or a file cabinet, and people seem to heavily rely on colleagues that they know and trust [24]. However, the emerging product development trends are pushing engineers to work with more people than ever before, but often with very limited knowledge of whom they are actually working with, what their collaborators know, and to what extent they can be trusted [24].

Furthermore, as highlighted by Granovetter [25], effective knowledge sharing is more likely to happen through distant and infrequent relationships and 'weak ties' [25], because they provide access to novel information through connection to larger groups. In contrast, 'strong ties' can only lead to redundant information because knowledge is shared predominantly within small groups where everyone knows what the others know [11]. Weak ties are, therefore, particularly interesting when it comes to product development activities, mainly because this is a field where knowledge workers are explicitly interested in avoiding redundancy and seeking novelty and innovation.

Weak ties can support the design team in collecting and interpreting the customer needs, i.e. the 'problem' to be solved. Larsson [11] has observed that the ability to access and to understand needs fundamentally depends on whom the design team talks to in the customer organization. The 'customer' is not a singe individual, but rather composed of many people, typically dispersed in the customer network, who have different information about what the customer want. Providing means to develop ties with 'lead-users' [26], able to offer their advice and experience to innovate the product, can enhance the capability of the team to understand how to add "value" to the customer, identifying much earlier the right problem solving strategy to pursue.

Weak ties can also provide access to 'hidden experts' around the enterprise that can support the team in coping with a given design problem. The foremost experts on the product/service might be outside of the official job description, not even on the company's payroll [27], as highlighted during the empirical study at Company A:

\begin{abstract}
"Our group comprises also a naval department. Once it developed an innovative and heavily press released engine model, which broke down at his first public ride. Then, at the annual corporate Christmas party, a group of naval engineers met experts from our aerospace division and started to discuss the accident. Plenty of issues not properly considered during design popped up. They went back to work, introduced a few modifications, and it worked. I think we need these Christmas parties online. We have the right competences within our enterprise, but we are not good at finding them."
\end{abstract}

Nurturing weak ties becomes crucial for the design team to locate and exploit the hidden competencies in the extended organization and for the overall success of any complex development initiative.

\section{Social technologies for product development: a literature review}

Many organizations have started to investigate the use of bottom-up, social technologies in their working environment. McAfee [28] summarizes the rising company interest in the use of Web 2.0 tools for generating, sharing and refining knowledge in a global setting with the term Enterprise 2.0, defined as: "the use of emergent social software platforms within companies, or between companies and their partners or customers" [28].

Many authors have further discussed the impact of social technologies and bottom-up concepts on knowledge management. Shimazu and Shinichi [29], for instance, have introduced a knowledge management model in the context of the Web 2.0 age that can expand collective intelligence in a positive spiral by closely linking it to knowledge extraction from various communication tools and job systems. The Knowledge 2.0 [30] principles have been further explored from a generic company perspective by several authors, such as Scherp [31], Sotirios [32] and Richards [33].

In the product development domain, the emerging interest towards social and bottom-up applications has been highlighted by a recent McKinsey [34] survey, showing that more than $2 / 3$ of 1700 companies interviewed worldwide during 2008 have investigated or deployed Web 2.0 tools to support their product development activities. Hinchcliffe [35] calls this trend "Product Development 2.0", a concept that embodies the use of social media to harness the collective intelligence of the development team, involving all the 
product stakeholders - users, producers, and technologists - into the creation of the product.

Online consumer communities are considered a major source of inspiration for the designers [36], thus crowdsourcing [37] represents one of the most intuitive ways to use bottom-up tools for the benefit of product development. As widely acknowledged in the software domain, Web 2.0 can leverage the role the crowd plays in the innovation process by lowering the threshold for outsourcing the design task to a community through an open call [38]. Dell IdeaStorm [39] represents an example of how this concept may be exploited in an early software design phase. Several top companies, such as Microsoft, Apple or IBM, have made extensive use of social media to get feedback from the customer and to share ideas with lead users ahead of beta testing [40]. In manufacturing, crowdsourcing applications have been used to gather innovations for both products and services [41] [42], even by means of virtual prototypes online [43].

Similarly, many companies have started to implement Web 2.0 tools to harvest product and process ideas from their employees, to distribute them through the organization, to have them evaluated by peers or formal review teams, and to eventually improve their internal procedures. The Microsoft Quest internal communications system [44], the wiki environment proposed by Ciavola et al. [45], and the wiki-like annotation tool advised by Maalej [46] represent examples of how a lightweight knowledge sharing approach can enhance collaboration across distributed development teams.

Social bookmarking applications, such as IBM Dogear [47], have been developed to support learning, sharing and collaboration between researchers and professionals. Online forums are used to share product knowledge with the users in the customer support phase [48], as well as to yield deeper insights when measuring past and present patterns of customer experience [49]. Microblogging functionalities are also implemented to leverage connections and facilitate knowledge sharing between different organizational areas [50].

Web 2.0 technologies can play a crucial role in enhancing the way product development projects are documented [51] [52]. Wiki-style collaboration tools have been often proposed to create assessment reports [53] or to address the problems associated with maintaining rule-based systems as they grow [33]. They have been found to enhance the team's shared understanding of the product to be developed, and to support faster design iterations and better collaboration in an early stage [54].

Several authors promote their use to enhance knowledge retrieval and to locate information just when needed. The key element for successful reuse is to understand a designer's reuse intention, which is not merely expressed by few keywords in a query. Context-based applications [55], therefore, have been developed and used to support the in-context delivering of relevant knowledge from terminated projects, as a means to improve future design activities [56].

Eventually, CAD/PDM software providers are exploring the possibility to leverage social interaction and collaborative features among global design teams, complementing their tools with Web 2.0 applications. Vuuch (http://www.vuuch.com), for instance, is a plugin for Pro/ENGINEER or Dassault Systemes' SolidWork that initiates, monitors, and manages design discussions directly from the CAD environment by associating them to the product Bill of Material.

\section{SWOT analysis}

The SWOT framework has been used to collect and summarize the main findings from the empirical study. Strengths (S) and Opportunities (O) gather those factors that are favorable to the implementation of a more bottom-up knowledge sharing approach, while Weaknesses (W) and Threats (T) mention aspects unfavorable to a more open strategy to knowledge management. Strengths (S) and Weaknesses (W) list major lessons learned related to the intraorganizational implementation of lightweight tools at Company A, while Opportunities (O) and Threats (T) highlight key areas of interest and inhibitors - both at Company A and B - related to the possibility of scaling up the adoption of social technologies to a crosscompany level.

\subsection{Strengths}

In complex and cross-functional development projects social media are appreciated for their ability to leverage networking across the enterprise, supporting newcomers in exploiting the connections of more experienced engineers. As acknowledged in the empirical study, they can reduce the time needed to search for experts and knowledge owners outside the usual designer's range of connections:

\footnotetext{
"We have tested social software functionalities with some of our competence centres for internal questions. Instead of just talking to man next door, we can address someone who is faster and more acknowledgeable to answer them."
} 
It has also been observed that social technologies facilitate information reuse in a new project context [24] by highlighting the 'social' processes related to information creation (e.g., by capturing the 'knowwhy' and linking knowledge elements to their owners), A major complaint against traditional document repositories is that they are typically undecipherable to people outside the project, and even to the original project members after time has passed [57]. People leave the organization, new members join the partnership and new requirements emerge along the way, making increasingly important to record the context related to such content [58]. Social technologies are seen as important enablers for capturing and semi- structuring contextual and conversational knowledge [59] that traditional systems usually fail to record and store [60][61].

\begin{abstract}
"Blogs and wiki are powerful tools to pick up coffee machine talks and to increase the network around a certain problem area... they are good tools to capture information, you can put things in a more structured way than just talks... It's about keeping information in order in relation to each other, whether referring to PDM or PLM."
\end{abstract}

The ability of keeping existing product/service knowledge up to date has also been indicated as a major strength of a bottom-up strategy. The establishment of self-regulating communities across the extended organizations actively contributes in keeping knowledge elements active and dynamic by incorporating experiences and discussions while applying them in specific situations [62].

Additionally, the respondents appreciate the mashup capabilities of these tools as means to tackle the problem of information overload [63]. Mash-ups can facilitate knowledge reuse (pushing relevant knowledge elements to the users at the right time in the right place), increase the visibility of knowledge elements from heterogeneous sources (aggregating lessons learned and best practices from different life cycle phases) and improve their analysis, taking advantage of associative processing.

Social technologies have also been advocated to leverage creativity across extended organizations through crowdsourcing. Most of the respondents noticed that crucial lifecycle knowledge is rarely straightforwardly fed back to the engineering team. Social technologies can enhance this process, enabling the "front row" (e.g., salesmen, technicians, customer support) to record, share and communicate facts and experiences back to the designers. Blogs, wikis or forums are not domain- or discipline-specific, thus they can be used outside the boundaries of the traditional knowledge management systems to collect ideas, needs and opportunities.

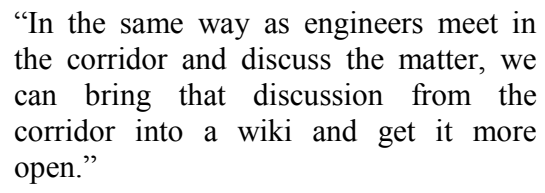

The empirical study has confirmed that blogs are preferably used to capture and disseminate expert insights and observations [64]. Wikis tend to be used as 'repositories' to collect critical issues from project meetings as well as spaces to collaboratively grow ideas for future products and to define and refine best practices from the different lifecycle phases, facilitating idea and experience sharing among the stakeholders across the lifecycle.

\subsection{Weaknesses}

The empirical study has identified two major factors inhibiting the straightforward implementation of lightweight collaborative environments in a product development setting: (1) a company culture that discourages working with unstructured information; (2) individuals that refuse to take an active part in open dialogues due to time concerns.

Informal knowledge sharing is inhibited by a company culture that considers socializing during working hours as a spare time activity, rather an attempt to exploit key social capital. Younger employees have appeared to be more acquainted with and prone to adopt Web 2.0 tools in their everyday activities. However, they also appeared to be the ones more rapidly absorbing the corporate culture when hostile to the idea, especially when considering the tool not suitable for the "engineering work".

Furthermore, in presence of strict deadline, the use of social tools is mostly seen as a burden for the engineers. Under constant time pressure, the use of the 'official' document management systems is prioritized and knowledge capture tends to be reduced to a minimum. Wikis, blogs and forums are thus seen as environments where users are forced to "duplicate" information already existing in other sources, thus they tend to be ignored.

Knowledge quality was also found as a major weakness, which strongly limits the real life implementation of these tools:

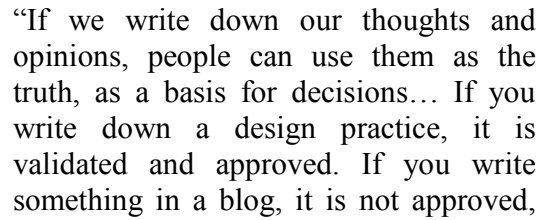


but it is quite obvious that you cannot use it as it is. But the wiki... if somebody writes: "you should design a mount like this", someone else may use such information even if no one approves it. It is not a ranking system. Either you can design or you cannot."

A major fear is that social technologies tend to be dominated by the loudest and most persistent voices, leaning towards personal opinions and interpretations rather than verified facts. This problem is particularly remarkable within the domain studied (the aerospace industry) because design decisions strongly affect passenger safety and thus require a very solid, objective and verified knowledge base (i.e., they must not be biased by personal comments, impressions or unverified facts). Without clear indications of what can or cannot be shared, users tend to play a safer game and rely on the information from more 'official' knowledge sources.

\subsection{Opportunities}

In a cross-functional and cross-organizational setting, a more bottom-up knowledge sharing approach is advocated to positively impact the way information is prepared and used in a Stage-Gate ${ }^{\circledR}$ process [65], supporting a more collaborative and iterative process for what concerns knowledge validation.

The study has shown that this activity is largely dominated by personal relationships and physical interactions. Engineers are used to turn to people they know and trust to confirm knowledge they possess. However, these people are difficult to find in product development setting that spans across several companies and functions.

Social technologies offer a unique opportunity to bring people together in a common forum to collectively answer questions such as: What do we know from previous projects? What are we lacking? Has anything already been done related to this context?

\begin{abstract}
"People may have very personal ideas on how an engine mount or a boss should be designed. Being able to formalize this unstructured information would mean that very early other people could say: "this is good" or "this is completely wrong"... If we would be able to use these social functionalities properly, the discussion could rise much earlier than it happens today... We could keep track of the context in which information is generated."
\end{abstract}

Social technologies might enable decisions makers to deliberate with greater awareness and fewer ambiguities and uncertainties. By making downstream knowledge available in an earlier phase, simulation models could be populated and used much earlier than what happens today, which would ultimately increase the design team capability to prevent mistakes later in the lifecycle. Failures might be predicted - and corrective actions put in place - even before a product/service is operated.

Social tools might significantly contribute in shortening the start-up time for complex development projects as well. The team might be able to more easily glance through the knowledge baseline, e.g. by using context-based search engines to retrieve knowledge elements relevant for the task/gate it is operating in. Web 2.0 might also support a more serendipitous discovery of knowledge across applications and domains, e.g. matching heterogeneous knowledge elements together on the basis of their tag commonality.

Eventually, social technologies can help the project management in locating capabilities across the extended organization. Engineers and designers might use social network applications to constantly update their profile description, providing more up-to-date information on background, experience and interests compared with more top-down competence databases.

\subsection{Threats}

Knowledge leakage represents the most obvious threat related to the implementation of bottom-up strategy in a multi-company partnership. Mishandling RSS feeds, for instance might push confidential information to unknown subscribers in the network, exposing core know-how or customer requirements. Hence companies tend to be over-defensive in using these approaches, prescribing rigid set of rules concerning what can be spread and what can be not, eventually spoiling the initiative of all its bottom-up potential.

The limited longevity of the knowledge stored in the lightweight system has been also discussed in the study. An aircraft can be maintained in service for more than 40 years. If problems happen, engineers have to trace the issue back to its roots, perhaps in a design document that is twenty years old. Important information about "why" a certain decision was taken might be too dispersed - or hidden by other elements to be retrievable.

At a more personal level, shared spaces that allow each and every individual to see what others have written or what they have commented upon might trigger self-censorship behaviors. Individuals might avoid sharing remarkable knowledge elements purposefully, or might moderate the quality of 
knowledge elements to benefit the interests of their team/company. People might also tend to not expose themselves openly because misinterpreted words might affect personal communication or damage professional reputation [66].

\section{Discussion}

The outcome of the SWOT analysis is summarized in Table 1:

\section{Table 1. SWOT analysis summary}

\begin{tabular}{|c|c|}
\hline \begin{tabular}{l}
\multicolumn{1}{c}{ Strengths } \\
- Support young engineers in \\
exploiting the network of \\
connections of the more \\
experienced ones. \\
- Record and share contextual \\
knowledge (mainly know-why \\
and know-who). \\
- Capture and structure \\
conversational knowledge. \\
- Keep existing product/service \\
knowledge up to date. \\
- Reduce information overload. \\
- Support the crowdsourcing of \\
creative and innovative ideas.
\end{tabular} & $\begin{array}{l}\text { Weaknesses } \\
\text { - Strongly depend on the } \\
\text { individuals' motivation in taking } \\
\text { an active part in open } \\
\text { dialogues. } \\
\text { - Strongly depend on the } \\
\text { company's capability to } \\
\text { establish a culture of working } \\
\text { with unstructured information. } \\
\text { - Is dominated by personal } \\
\text { opinions and interpretations } \\
\text { rather than facts, affecting } \\
\text { knowledge reliability and } \\
\text { quality. }\end{array}$ \\
\hline $\begin{array}{l}\text { Opportunities } \\
\text { - Support a more collaborative } \\
\text { and iterative process for } \\
\text { knowledge validation. } \\
\text { - Facilitate the collection of } \\
\text { lessons learned from the } \\
\text { extended organization to } \\
\text { reduce ambiguities and } \\
\text { uncertainties in the decisions. } \\
\text { - Support the design team in } \\
\text { recognizing relevant knowledge } \\
\text { elements for the project context. } \\
\text { Locate the individuals with the } \\
\text { right capabilities and skills to } \\
\text { contribute to the project. }\end{array}$ & \begin{tabular}{l}
\multicolumn{1}{c}{ Threats } \\
Facilitate knowledge leakage. \\
Do not adequately store and \\
classify knowledge over long \\
periods of time. \\
Triggers self-censorships \\
behaviors.
\end{tabular} \\
\hline
\end{tabular}

The analysis shows that 'social product development' is largely about providing technologies that facilitate the empathic discovery of knowledge in a variety of knowledge sources spread across the many corners of the extended enterprise.

By comparing strengths, weaknesses, opportunities and threats, the SWOT contributes to the identification of the low-hanging fruits of such a bottom-up knowledge sharing strategy, which can be used as a starting point for defining how the requirements for a sustainable lightweight knowledge sharing system should look like.

As shown in the SWOT, the overall purpose of social technologies is not to straightforwardly replace CAD software and data warehouses, but rather to provide more visibility and enrich the data contained therein, by capturing and framing the conversation in which the design information is produced. More in detail, the priority lies in the development of bottom-up tools (and related guidelines) able to lower the threshold for gathering contextual information in relation with customer needs, lessons learned and best practices.

The analysis also spotlights the new role played in the modern organization by all those individuals from production, marketing, sales, maintenance, disposal, etc. - who possess relevant knowledge for the development of product/service offers. When approaching the design problem from a lifecycle perspective, their responsibility is expanded to cover a wider range of issues, thus they are increasingly asked to play the role of 'knowledge brokers' in the extended organization, making their knowledge available to a larger network of peers.

How should their performances be evaluated? How should incentives be established? How should this modern 'knowledge worker' be trained? The Stanford University's 'd.school' ambition to create 'T-shaped' people [67] expresses well the need to train individuals in different parts of the organization able to assimilate and integrate different perspectives in their work. Tshaped people "maintain the depth and focus of a single discipline while adding a 'crossbar' of design thinking that drives the integration of multiple perspectives into solving real problems." [67]. The successful adoption of a bottom-up strategy when it comes to product/service development strongly depends from the ability to create a broader 'empathy' (the horizontal part of the T) when it comes to respecting, valuing and embracing a diverse set of disciplines and perspectives.

This modern knowledge workers need knowledge sharing technologies whose structure can evolve over time, as an almost organic response to their activities, practices and interests. This need for flexibility is not addressed by the current knowledge engineering systems, but could be instead satisfied by modern Web 2.0 solutions. As observed in the study, blogs, wikis, social networks, RSS feeds, tags, microblogs, instant messages, discussion forums and social bookmarks seem to perfectly fit with the evolution of product development practices, and can therefore play a crucial role to enhance engineering activities across functional boundaries.

\section{Conclusions}

The paper has discussed the role of weak ties as enablers for more collaborative and innovative crossfunctional development projects. 
The findings confirm that, although social technologies are not intended to replace traditional $\mathrm{CAD} / \mathrm{PDM} / \mathrm{PLM}$ systems, they can improve the knowledge baseline for complex product development projects, essentially providing the necessary context to leverage the way information is interpreted and processed by the engineers to solve the task at hand. The empirical study has shown that these technologies can support designers in capturing and semi-structuring conversational knowledge from a larger stakeholders' base, and to communicate it in a meaningful way for the design task. Examples have been also given in terms of how social tools can be applied in a StageGate ${ }^{\circledR}$ process [65] to increase the quality of early design decisions, that is, by collecting facts, opinions and suggestions on how to deal with wicked design problems before the gate meeting.

Web 2.0 tools can help engineers in finding people who tag items the same way they do, in identifying hidden experts by reading comments in a blog, or in finding social groups with similar interests by browsing their bookmarks collection. From a development process perspective, these mechanisms can leverage the way the design team identify the needed expertise in extended organization, the way the "context" of the information stored in databases and repositories is captured and managed, as well as the way knowledge assets are validated in a collaborative environment.

The study has also outlined a general lack of understanding of how such technologies could be implemented to support everyday engineering activities, that is, "socializing with a purpose". In spite of the increasing interest towards bottom-up concepts, today's perception of weak ties as enablers for more innovative and effective development processes is particularly low, even in cross-organizational projects where this need might appear more evident at a first look.

The risk that proprietary know-how could pop-up somewhere in the network for the benefits of the competitors is the major inhibitor for the implementation of social tools at the workplace. This asks for devising better policies and guidelines on how these technologies shall be used within and across the design teams.

In the light of these findings, in the close future the research will focus on three major questions arisen from the empirical study: 1) How knowledge elements can be aggregated in a meaningful way and managed along the product lifecycle, taking care of trust and security issues? 2) How their quality and maturity can be assessed? 3) How to enhance user commitment in the Web 2.0 initiative?
A software demonstrator integrating some of the key mechanisms highlighted during the study is under development, mainly with the purpose of collecting live feedback from engineers and designers on the use of social tools as enablers for more effective and efficient cross-functional product development projects.

\section{Acknowledgements}

The research is supported by VINNOVA (Swedish Agency for Innovation Systems), through the FASTE Laboratory at Luleå University of Technology.

\section{References}

[1] T. Khanna, R. Gulati, N. Nohria, "The dynamics of learning alliances: competition, co-operation, and relative scope", Strategic Management Journal, Vol. 19, 1998, pp. $193-210$.

[2] G. Hamel, Y.L. Doz and C.K. Prahalad, "Collaborate with your competitors and win", Harvard Business Review, Vol. 67, 1989, pp. 133-139.

[3] Rolls Royce, "International Aero Engines V2500", available at: http://www.rollsroyce.com/civil/products/largeaircraft/v2500/, accessed 12th June 2011 .

[4] J. Bilien and R. Matta, "The CFM56 Venture", Proceedings of the Aircraft Design, Systems, and Operations Conference, Seattle (WA), 1989.

[5] V. Acha. A. Davies, M. Hobday and A. Salter, "Exploring the capital goods economy: complex product systems in the UK", Industrial and Corporate Change, Vol.13, 2004, pp. 505-529.

[6] T.S. Baines, H.W. Lightfoot, S. Evans, et al., "State-ofthe-art in Product-Service systems", Journal of Engineering Manufacture, Vol. 211, 2007, pp. 1543-1552.

[7] Å. Ericson, T. Larsson, "A service perspective on product development: towards functional products", Proceedings of the 12th International Product Development Conference (IPDM), Copenhagen (DK), 2005.

[8] M. Lindahl, E. Sundin, A. Öhrwall Rönnbäck, G. Ölundh, and J. Östlin, "Integrated Product and Service Engineering the IPSE project", Proceedigns of the Sustainable Consumption Research Exchange Workshop (SCORE!), Copenhagen (DK), 2006.

[9] M.M. Webber and H. Rittel, "Dilemmas in a General Theory of Planning”, Policy Sciences, Vol. 4, 1973, pp.155169.

[10] O. Isaksson, T.C. Larsson and A. Öhrwall Rönnbäck, "Development of product-Service Systems: Challenges and Opportunities for the manufacturing firm", Journal of Engineering Design, Vol. 20, No. 4, 2009, pp. 329-348. 
[11] A. Larsson, Å. Ericson, T.C. Larsson and D. Randall, "Engineering 2.0: exploring lightweight technologies for the Virtual Enterprise", Proceedings of International Conference on the Design of Cooperative Systems (COOP), Carry-leRouet (F), 2008.

[12] S. Bell, Lean enterprise systems: using IT for continuous improvement” John Wiley \& Sons, Hoboken, 2006.

[13] J. Surowiecki, The Wisdom of Crowds: Why the Many Are Smarter Than the Few and How Collective Wisdom Shapes Business, Economies, Societies and Nations, Doubleday, New York, 2004.

[14] D.W. Pickton and S. Wright, "What's SWOT in strategic analysis?", Strategic Change, Vol. 7, 1998, pp. 101109 .

[15] M.M. Helms and J. Nixon, "Exploring SWOT analysis where are we now?", Journal of Strategy and Management Vol. 3, No. 3, 2010, pp. 215-251.

[16] P. Jarzabkowski and D.C. Wilson, "Actionable Strategy Knowledge: A Practice Perspective", European Management Journal, Vol. 24, No. 5, 2006, pp. 348-67.

[17] T. Hill and R. Westbrook, "SWOT Analysis: It's Time for a Product Recall", Long Range Planning, Vol. 30, No. 1, 1997, pp. 46-52.

[18] N. Worren, K. Moore and R. Elliot, "When Theories Become Tools: Toward a Framework for Pragmatic Validity" Human Relations, Vol. 55, No. 10, 2002, pp. 1227-49.

[19] R.W. Oliver, "The real-time toolbox", The Journal of Business Strategy, Vol. 21, No. 2, 2000, pp. 7-10.

[20] S.L. Star and J.R. Griesemer, "Institutional Ecology, 'Translations' and Boundary Objects: Amateurs and Professionals in Berkeley's Museum of Vertebrate Zoology, 1907-39", Social Studies of Science, Vol. 19, No. 3, 1989, pp. $387-420$.

[21] P.R. Carlile, "A Pragmatic View of Knowledge and Boundaries: Boundary Objects in New Product Development" Organization Science, Vol. 13, No. 4, 2002, pp. 442-455.

[22] A.P. Spee, P. Jarzabkowski, "Strategy tools as boundary objects”. Strategic Organization, Vol 7, No.2, pp. 223-232.

[23] S. Cook and J. Brown, "Bridging epistemologies: the generative dance between organizational knowledge and organizational knowing", Organization Science, Vol. 10, No. 4, 1999, pp. 381-400.

[24] A. Larsson, Engineering Know-Who: Why Social Connectedness Matters to Global Design Teams, Doctoral Thesis, Luleå University of Technology, Luleå, 2005.

[25] M. Granovetter, "The Strength of Weak Ties", American Journal of Sociology, Vol. 6, 1973, pp. 1360-1380.

[26] E. von Hippel, "Sticky information and the locus of problem solving: Implications for innovation", Management Science, Vol. 40, No. 4, 1994, pp. 429-439.
[27] R. Mayfield, "Enterprise Microblogging Whitepaper", Socialtext, 2009.

[28] A. McAfee, "Enterprise 2.0: The Dawn of Emergent Collaboration", MIT Sloan Management Review, Vol. 47, No. 3, 2006, pp. 21-28.

[29] H. Shimazu and K. Shinichi, "KM2.0: Business knowledge sharing in the Web 2.0 age, NEC Technical Journal, 2007.

[30] M. Levy, "Web 2.0 Implications on Knowledge Management", Journal of Knowledge Management, Vol. 13, No.1, 2009, pp.120-134.

[31] A. Scherp, F. Schwagereit and T. Ireson, "Web 2.0 and traditional knowledge management processes", Proceedings of the 1st Workshop on Knowledge Services \& Mashups (KSM), Solothurn (CH), 2009.

[32] P. Sotirios and A.S. Alya, "Determinants of Knowledge Sharing Using Web 2.0 Technologies", Journal of Knowledge Management, Vol. 13, No. 4, 2009, pp. 52-63.

[33] D. Richards, "A Social Software/Web 2.0 Approach to Collaborative Knowledge Engineering", International Journal of Information Sciences, Vol. 179, 2009, pp. 2515-2523.

[34] J. Bughin, How Companies are benefiting from Web 2.0, McKinsey Global Survey results, 2009.

[35] D. Hinchcliffe, "Product Development 2.0", Communications \& Strategies, Vol. 65, 2007, p. 105.

[36] D.A. Pitta and D. Fowler, "Online consumer communities and their value to new product developers", Journal of Product \& Brand Management, Vol. 14, No. 5, 2005, pp. 283-291.

[37] J. Howe, "The rise of crowdsourcing”, Wired Magazine, Issue $14.06,2006,5 \mathrm{p}$.

[38] M.V. Ribiere and F.D. Tuggle, "Fostering innovation with KM 2.0”, VINE, Vol. 40. No. 1, 2010, pp. 90-101.

[39] P.M. Di Gangi and M. Wasko, "Steal my idea! Organizational adoption of user innovations from a user innovation community: A case study of Dell IdeaStorm", Decision Support Systems, Vol. 48, No. 1, 2009, pp. 303312 .

[40] D. Smith and R. Valdes, Web 2.0: Get ready for the next old thing, Gartner Research Paper, Stamford, 2005.

[41] Y. Awazu, P. Baloh, K. Desouza, C.H. Wecht, K. Jeffrey and S. Jha, "Information-Communication Technologies Open Up Innovation". Research-Technology Management, Vol. 52, No. 1, 2009, pp. 51-58.

[42] A. Mamgai and J. Sanjog, "Web 2.0: Reshaping Organization Strategy in the Flat World", SETLabs Briefings, Vol. 7, No. 2, 2009.

[43] J. Füller, M. Bartl, H. Ernst and H. Mühlbacher, "Community based innovation: How to integrate members of virtual communities into new product development", Electronic Commerce Research, Vol. 6, 2006, pp. 57-73. 
[44] K. Patrick and F. Dotsika, "Knowledge Sharing: Developing from within", The Learning Organizations Journal, Vol. 14, No. 5, 2007, pp. 395-406.

[45] B.T. Ciavola and J.K. Gershenson, "Establishment of an Open, Wiki-Based Online Resource for Collaboration in the Field of Product Family Design", Proceedings of the 17th International Conference on Engineering Design (ICED), Stanford (CA), 2009.

[46] W. Maalej and H.J. Happel, "A Lightweight Approach for Knowledge Sharing in Distributed Software Teams", Proceedings of the 7th International Conference on the Practical aspects of Knowledge Management (PAKM), Yokohama (J), 2008, pp. 14-25.

[47] D.R. Miller, Dogear: Social Bookmarking in the Enterprise, available at: www.research.ibm.com/jam/601/p28-millen.pd.

[48] J. Bernoff and C. Li, "Harnessing the Power of the OhSo-Social Web", MIT Sloan Management Review, Vol. 49, No. 3, 2008.

[49] C. Meyer and A. Schwager, "Understanding Customer Experience", Harvard Business Review, Vol. 85, 2007, pp. $117-126$.

[50] J. Müller and A. Stocker, "Enterprise Microbloging at Siemens, Building Technologies division: A descriptive case study", Proceedings of the I-KNOW conference, Graz (A), 2010 .

[51] N. Høimyr and P.L. Jones, "Wikis supporting PLM and Technical Documentation", Proceedings of the Product Data Technology (PDT) Europe Conference, Geneva (CH), 2007.

[52] A. Albers, B. Ebel and C. Sauter, "Combining process model and semantic wiki, Proceedings of the 10th DESIGN Conference, Dubrovnick (HR), 2010.

[53] I.T. Hawryszkiewycz, "Lightweight Technologies for Knowledge Based Collaborative Applications", Proceedings of the $9^{\text {th }}$ IEEE International Conference on E-Commerce Technology and the 4th IEEE International Conference on Enterprise Computing, E-Commerce, and E-Services, Tokyo (J), 2007, pp. 255-264.

[54] C. Walthall, C. Sauter, T. Deigendesch, A. Albers, K. Ramani, "Survey Of Wikis As Design Support Tool", Proceedings of the 17th International Conference on Engineering Design (ICED), Stanford (CA), 2009.

[55] B. Schillit, N. Adams, and R. Want, "Context-Aware Computing Applications", Proceedings of the $1^{\text {st }}$ International Workshop on Mobile Computing Systems and Applications, Santa Cruz (CA), 1994, pp. 85-90.
[56] R. Redon, A. Larsson, R. Leblond and B. Longueville, "VIVACE Context Based Search Platform", Proceedings of the $6^{\text {th }}$ International and Interdisciplinary Conference on Modeling and Using Context (CONTEXT), Roskilde (DK), 2007.

[57] J. Grudin, "Enterprise knowledge management and emerging technologies", Proceedings of the $39^{\text {th }}$ Hawaii International Conference on System Sciences, (HICSS), Washington (D.C.), 2006.

[58] G. Goldkuhl and E. Braf, "Contextual knowledge analysis - understanding knowledge and its relations to action and communication", Proceedings of 2nd European Conference on Knowledge Management, Bled (SLO), 2001.

[59] C. Wagner, "Breaking the Knowledge Acquisition Bottleneck Through Conversational Knowledge Management", Information Resources Management Journal, Vol. 19, No. 1, 2006, pp. 70-83.

[60] T. Davenport and L. Prusak, Working Knowledge, Harvard Business School Press, 1998.

[61] S. Liao, "Knowledge management technologies and applications-literature review from 1995 to 2002", Expert Systems with Applications, Vol. 25, 2003, pp. 155-164.

[62] Y. Barnard and A. Rothe, "Knowledge Management in engineering: supporting analysis and design processes in innovative industries", In P. Cunningham, P., Cunningham, M. and Fatelnig, P., Building the Knowledge Economy, Issues, applications, Case studies, IOS Press Amsterdam, 2003, pp. 931-938.

[63] P. Maes, "Agents that reduce work and information overload", Communications of the ACM, Vol. 37, No. 7, 1994, pp. 31-40.

[64] L. Efimova and J. Grudin, "Crossing Boundaries: A Case Study of Employee Blogging", Proceedings of the 40th Hawaii International Conference on System Sciences (HICSS), Big Island (HI), 2007.

[65] R.G. Cooper, "Perspective: The Stage-Gate ${ }^{\circledR}$ Idea-toLaunch Process-Update, What's New, and NexGen Systems", Journal of Product Innovation Management, Vol. 25, 2008, pp. 213-232.

[66] G. Disester, "Individual and Social Barriers to Knowledge Transfer", Proceedings of the 34th Hawaii International Conference on System Sciences (HICSS), Big Island (HI), 2007.

[67] T. Winograd, "Design Education for Business and Engineering Management Students: A New Approach", Interactions, January + February, 2008. 